\title{
Climatology of ionosphere over low-latitude (Kolkata) using FORMOSAT-3/COSMIC satellite observation
}

\author{
Gopal Mondal ${ }^{1, *}$, Manojit Gupta $^{2}$ and Goutam Kumar Sen ${ }^{1}$ \\ ${ }^{1}$ School of Oceanographic Studies, Jadavpur University, Kolkata 700 032, India. \\ ${ }^{2}$ Department of Mathematics, Jadavpur University, Kolkata 700 032, India. \\ ${ }^{*}$ Corresponding author.e-mail: gopalmondal18@gmail.com
}

\begin{abstract}
We have analyzed the diurnal, monthly, and seasonal variation in NmF2, HmF2, and IECs parameters derived from the COSMIC-RO observation over the low-latitude (Kolkata) region during 2008-2012 and compared the result with the IRI-2007 model output. In general, during HSA period the seasonal averaged model outcome prominently overestimates the observed values throughout the day, except HmF2, while in LSA period it is confined to post-noon hours. The differences between diurnal-dip and diurnal-peak values of all these parameters are considerably higher in the model outcomes than those of observed values, especially during increasing solar activity. In addition, the monthly averaged NmF2, BIEC, and TIEC values at noon and midnight, obtained from the both options, exhibit semi-annual variation, which are in good agreement with some earlier studies, whereas HmF2 shows annual variability for all solar activity. Moreover, the similarities and dissimilarities observed in variation pattern, particularly during 2011 and 2012, can help the research community to understand the recent trends of ionospheric parameters and develop the IRI model with more efficiency to fit the observed profile in a better way.
\end{abstract}

\section{Introduction}

The ionosphere is a natural plasma medium surrounding the Earth. Its height, density, and other delicate characteristics are severely affected by the state of the Sun. Lower atmosphere and other layers of the space also have a vital relation with the ionosphere. The increasing dependencies of man and his different tools to utilize the presence of ionosphere have encouraged the research community to understand its variability on a long term (climatological) basis at different spatial zones. Additionally, the knowledge of climatological variation in different ionospheric parameters is essential to extract information about instantaneous changes in electron $(\mathrm{Ne})$ concentration due to lower as well as upper atmospheric forcing. The International Reference Ionosphere (IRI) model continuously provides us valuable information about the state of the instantaneous ionosphere throughout the globe (Bilitza and Reinisch 2008; Kenpankho et al. 2011). In this model, the input variables are incorporated from ground and space-based observations situated at different locations of the Earth. In that respect, equatorial ionosphere is the most important as occurrence of various irregularities in this region is prevalent. Some authors (Bhar et al. 1970; Chakraborty et al. 1999; Das et al. 2010; Paul et al. 2011) have extensively studied about different features of ionospheric irregularities over the Equatorial Ionization Anomaly (EIA) region using VHF scintillation technique in the recent past. Among these studies, Chakraborty et al. (1999) highlighted the trends of Total Electron Content (TEC) variability over the Indian EIA region due to the variation of solar activity, analyzing long-term

Keywords. COSMIC; HmF2; NmF2; BIEC; TIEC; low-latitude. 
(13 years) observational data, whereas Paul et al. (2011) established the necessity of differential grid size around the northern crest of EIA region owing to sharper TEC gradient towards the pole. To date, the availability of ionospheric parameters in the Indian equatorial region is limited. The Low Earth Orbiting (LEO) satellite measurement may be an alternative solution not only to this problem but also to the effort of modification of IRI model. However, a few research works about the ionospheric variability for large time scale over this region have been done, which encouraged us to study the ionospheric variability for long-time basis using LEO satellite observation during 2008-2012. It may be mentioned here that in 2008, the Sun was quieter than in recent years and thereafter, its raising phase continued till 2012. However, the Low Solar Activity (LSA) period is necessary to display the natural variations in atmosphere as well as ionosphere. Kawamura et al. (2002) have extensively studied the ionospheric variability during LSA condition.

Recently, Sripathi (2012) in his study has made several attempts to reveal the seasonal, diurnal, and latitudinal variations in ionospheric Ne concentration with variation in altitude over Indian longitude during LSA phase in 2008. This study indicated an important phenomenon that the $\mathrm{Ne}$ concentration gets higher during vernal equinox compared to autumn equinox.

Using the digital ionosonde measurements, Sethi et al. (2004), Sethi and Dabas (2006) observed that the HmF2 variability was greater at midnight in comparison to daytime, and the bottom side TEC (BTEC) increased by a factor of more than two from moderate to High Solar Activity (HSA) conditions, over Delhi. In this study, they have also reported that BTEC has exhibited large day-to-day fluctuation at any given Local Time (LT).

Das Gupta et al. (2007) in their seminal study on ionospheric Ne content observed that equatorial ionosphere sustained not only maximum ionization but high TEC also and the gradient of EIA was extended both in horizontal and altitudinal directions. Moreover, the trough and crest phenomenon in EIA were sharper, which resulted in large temporal and spatial variations of the ionospheric electron content.

The central point of the present paper is to analyze the diurnal, monthly, seasonal, and yearly variation of ionospheric peak parameters: the peak $\mathrm{Ne}$ density (NmF2) and the height of peak Ne density (HmF2), BIEC and Topside Integrated Electron Content (TIEC) over the region $15^{\circ}-30^{\circ} \mathrm{N}$ and $80^{\circ}-95^{\circ} \mathrm{E}$, based on COSMIC satellite observations during 2008-2012, and comparison with IRI-2007 model output to validate our result. The data and method of analysis are mentioned in section 2 .
Results and discussion are shown in section 3, and the conclusion is given in section 4 .

\section{Data and method of analysis}

To examine the solar activity variation, the solar flux data at $10.7 \mathrm{~cm}$ (F10.7) have been taken from World Data Centre website (http://www.ukssdc. ac.uk) and the $\sum K p$ index data have been obtained from the Kyoto University website (http:// wdc.kugi.kyoto-u.ac.jp) to analyse the geomagnetic activity from 1 January, 2008 to 31 December, 2012.

In this study, we have used the LEO satellite Radio Occultation (RO) data. Six microsatellites termed Formosa Satellite 3 and Constellation Observing System for Meteorology Ionosphere, and Climate (FORMOSAT-3/COSMIC or F3/C in short) were launched from Vandenberg Air base, California at 0140UTC on 15 April, 2006. These satellites continuously monitor the globe with near about 2500 Vertical Electron Density (VED) profiles per day. The data used in this study (namely "ionPrf" data in COSMIC website, a level 2 vertical profile data) were obtained from the COSMIC website (http://www.cosmic.ucar.edu) for the time period from 1 January, 2008 to 31 December, 2012. The detailed description about this mission and its data processing techniques are presented in Aragon-Angel et al. (2009); Hwang et al. (2009); Chuo et al. (2011); and Sripathi (2012). However, a filtration technique to select suitable dataset has been imposed. As, the COSMIC is a LEO satellite with an orbital period of $\sim 100 \mathrm{~min}$, in order to detect the ionospheric variability at any specific location and time, the data from those orbital passes within a $15^{\circ} \times 15^{\circ}$ box centred at the point of location (Kolkata) are considered. First, the profiles, in which the geographic latitude (GEO_LAT) and geographic longitude (GEO_LON) of $\mathrm{HmF} 2$ lies within $15^{\circ}-30^{\circ} \mathrm{N}$, $80^{\circ}-95^{\circ} \mathrm{E}$ are sorted out. Thereafter, those profiles, which are associated to $F 10.7>150 \mathrm{sfu}$ and/or $\sum K p>30$ are discarded. The BIEC (1TECU= $1 \mathrm{E}+16 \mathrm{el} / \mathrm{m}^{2}$ ) and TIEC are calculated using the equation:

$$
(\mathrm{BIEC}, \mathrm{TIEC})=\int_{(\text {Balt, } \mathrm{HmF} 2)}^{(\mathrm{HmF} 2, \text { Talt })} N e(z) d z
$$

where Balt is the mean sea level altitude (MSL_Alt) at the bottom point of the profiles; HmF2, the MSL_Alt of NmF2 in F layer; and Talt, the MSL_Alt at the top point of the profiles. For COSMIC satellite, Talt is generally greater than 700 $\mathrm{km}$, whereas Balt has been taken as $70 \mathrm{~km}$.

In the late 1960s, the IRI project was initiated by the Committee on Space Research (COSPAR) 
and by the International Union of Radio Science (URSI) to avoid the uncertainties involving theoretical understanding of ionospheric processes and coupling to the regimes below and above. Detailed description about the IRI model, including information on the IRI newsletter and the IRI electronic mailer, can be found on the IRI homepage at http://IRI.gsfc.nasa.gov/ (Kenpankho et al. 2011). The corresponding predictions of IRI parameters are calculated from the IRI-2007 model (Bilitza and Reinisch 2008) using the location, date, and period of time as inputs to the model. For our study, model output is taken for the time period $2008-2012$ with Kolkata $\left(22.56^{\circ} \mathrm{N}, 88.36^{\circ} \mathrm{E}\right)$ as geographic location within $70-700 \mathrm{~km}$ altitude.

In the end, to figure out the variability in the monthly averaged profile at noon and midnight time, all those profiles are considered in which the observation-time range lies between 10.00-14.00 and 22.00-02.00 hrs LT, respectively.

\section{Result and discussion}

\subsection{Solar flux and $\sum K p$ index variations}

The solar flux at $10.7 \mathrm{~cm}(F 10.7)$ is a measure of solar activity, which has intimate relation to the ionization in the ionosphere. In figure 1, actual $F 10.7$ solar flux data (figure 1a) and $\sum K p$ index data (figure 1b) have been plotted over a period of 5 years (1 January 2008 to 31 December 2012). But, all available data, for which $F 10.7 \leq 150$ sfu and $\sum K p \leq 30$ have been taken into consideration for analysis. From the upper panel, one can observe that during the period 2008 to 2010, the solar flux values are mostly in the range of 65-92 sfu (1 sfu $=10-22 \mathrm{~W} \mathrm{~m}^{-2} \mathrm{~Hz}^{-1}$, which have been considered as LSA period, thereafter, flux increases gradually with rapid fluctuation in amplitude during the year 2011. Finally, in the year 2012, the flux varies between 87 and $183 \mathrm{sfu}$ (figure 1a). So in that respect, the beginning of year 2011 may be considered as the transition from LSA to HSA period. Also, there are some occasions where sharp increase in upper limits of the range are found, which could be due to 27 days solar rotation (Sripathi 2012). The bottom panel shows the day-to-day variability in $\sum K p$ index for the time range 2008-2012. However, for maximum days, $\sum K p$ values are less than 30 , which separates the days to be geomagnetically quiet or not. In 2011, ten days (maximum in comparison to other years) were attributed to geomagnetically disturbed days. Some earlier studies have reported that solar activity (Lee and Reinisch 2006, 2007)
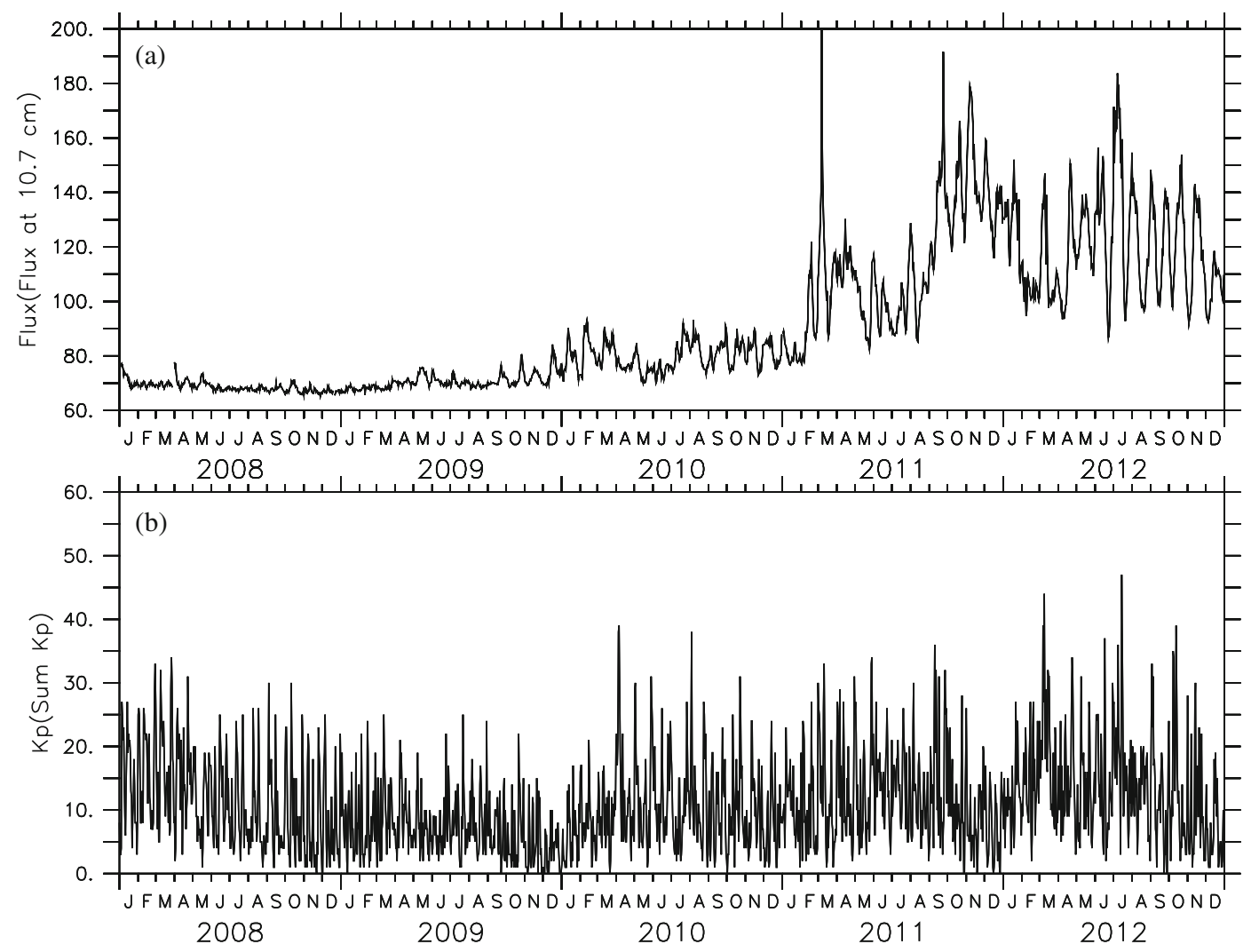

Days of the Years(2008-2012)

Figure 1. The variation of (a) daily solar flux ( F10.7) at $10.7 \mathrm{~cm}$ during 2008-2012 and (b) daily $\sum K p$ index for the years 2008-2012. 
and geomagnetic activity (Park et al. 2010; Sun et al. 2012) both have obvious association with ionospheric variability.

\subsection{NmF2 and HmF2 diurnal and seasonal variations}

The NmF2 and HmF2 are two crucial parameters in the study of ionospheric electrodynamics. Figure $2(\mathrm{a}-\mathrm{j})$ displays the season-wise diurnal variations in NmF2, obtained from COSMIC satellite measurement and IRI-2007 model output, for 2008-2012. The trend of diurnal variability is more or less similar for the both options with diurnal-dip during 05.00-07.00 hrs LT. Thereafter, NmF2 starts to increase and reaches the diurnalpeak at noon. The increase in $\mathrm{NmF} 2$, especially during 2011 and 2012, is due to high production rate at higher altitude in the presence of solar radiation during daytime compared to chemical losses ( $\mathrm{Su}$ et al. 1998; Lee and Reinisch 2006; Sripathi 2012). However, the diurnal-peak values of NmF2 in IRI-2007 model are relatively peaky with higher standard deviation around
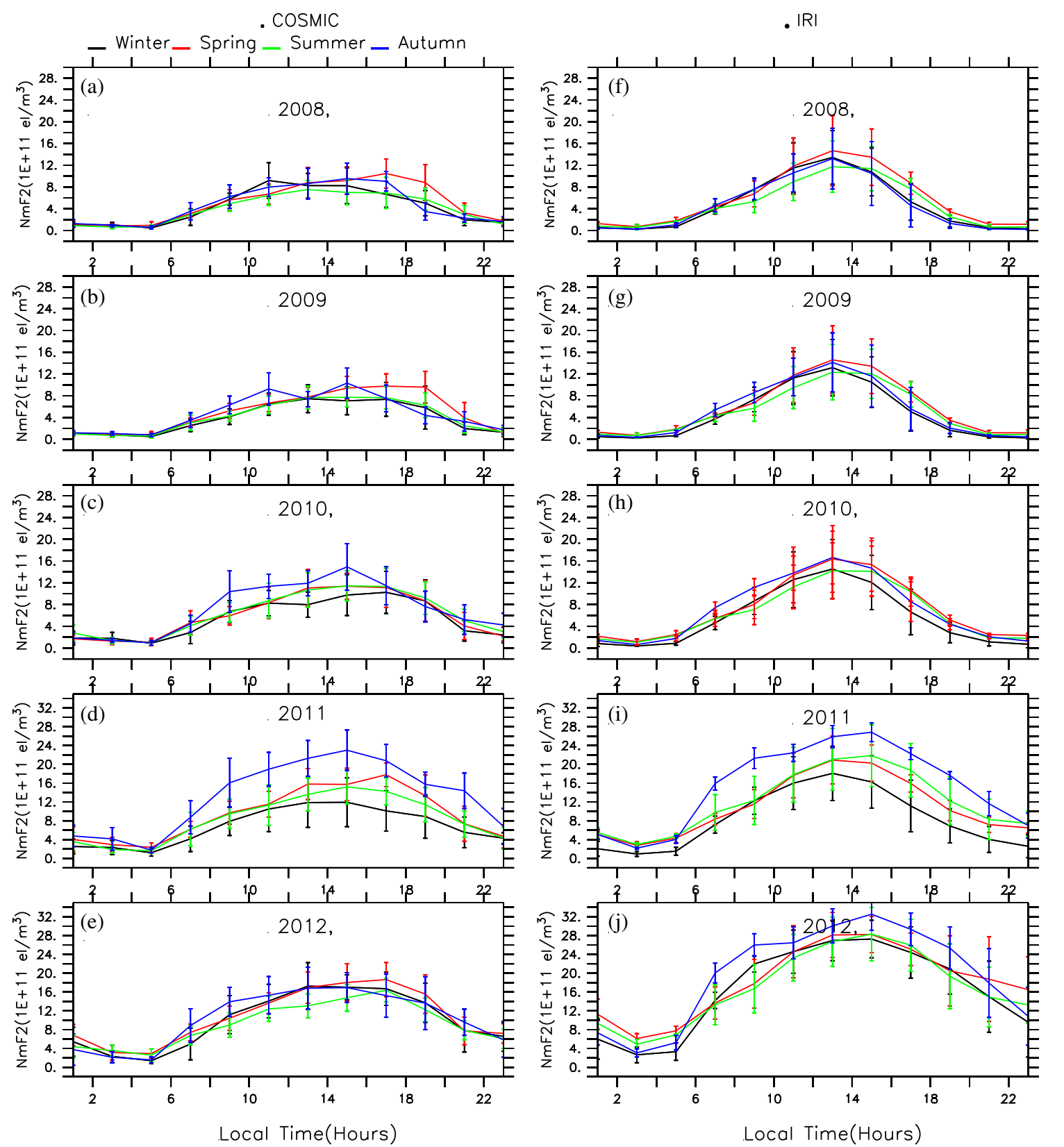

Figure 2. The diurnal variation in $\mathrm{NmF} 2$ using COSMIC-RO observations over low-latitude region $\left(15^{\circ}-30^{\circ} \mathrm{N}, 80^{\circ}-95^{\circ} \mathrm{E}\right)$ and IRI-2007 model output at Kolkata. The left panels are for COSMIC-RO measurements for the years: (a) 2008; (b) 2009; (c) 2010; (d) 2011 and (e) 2012. The right panels are for IRI-2007 model output for the years: (a) 2008; (b) 2009; (c) 2010; (d) 2011 and (e) 2012. Different colours represent different seasons. Vertical bars denote the standard deviation. 
9.00-17.00 hrs LT than those obtained from COSMIC-RO, during all the seasons throughout the observation period. But, the COSMIC-RO measurement shows higher standard deviation during the post-noon hours. The autumn season, apparent in rising period of the Sun, shows maximum NmF2 concentration (figure 2) in comparison to other seasons, while winter seasons exhibit minimum concentration. The deviations in seasonto-season diurnal values of $\mathrm{NmF} 2$, obtained from COSMIC-RO observations, with respect to winter have apparent trend to be larger during daytime (especially during post-noon hrs). In 2008 $\left(3.8 \mathrm{E}+11 \mathrm{el} / \mathrm{m}^{3}\right), 2009\left(3.8 \mathrm{E}+11 \mathrm{el} / \mathrm{m}^{3}\right)$ and 2012 $\left(1.9 \mathrm{E}+11 \mathrm{el} / \mathrm{m}^{3}\right)$, the maximum deviation occurred in spring, whereas in $2010\left(5.2 \mathrm{E}+11 \mathrm{el} / \mathrm{m}^{3}\right)$ and $2011\left(11 \mathrm{E}+11 \mathrm{el} / \mathrm{m}^{3}\right)$, it occurred during autumn. In comparison to COSMIC-RO measurements, the IRI-2007 model outputs interestingly display larger season-to-season deviations in $\mathrm{NmF} 2$ values. The significant solar flux fluctuations (figure 1a; $\mathrm{Su}$ et al. 1998; Lee and Reinich 2007; Chen et al. 2009) and the horizontal natural winds variability (Alken et al. 2008) in the low-latitude region play a sensitive role in ionospheric electrodynamics. So, noticeable differences between the observed results and model results have been detected in $\mathrm{NmF} 2$ variability.

In figure $3(\mathrm{a}-\mathrm{j})$, the values of $\mathrm{HmF} 2$ obtained from COSMIC satellite measurement and IRI-2007 model output, for different LT are plotted for the years, 2008-2012. The vertical bars at each of the average points of $\mathrm{HmF} 2$ represent corresponding standard deviation. The diurnal variations in $\mathrm{HmF} 2$ exhibit almost similar pattern for the both options, with twin occurrences of diurnaldips: one at post-sunrise (06.00-08.00 hrs LT) hours and another at sunset (18.00-20.00 hrs LT) time, whereas the two diurnal peaks are found to be at noon (12.00-14.00 hrs LT) and at midnight (22.00-02.00 hrs LT). In equatorial ionosphere, the $\mathrm{HmF} 2$ variation is intimately connected to the vertical $E \times B(E$ and $B$ are electric and magnetic fields, respectively; both are vector quantities) drift velocity variation because of the horizontal geomagnetic field lines and ionization due to solar radiation (Sethi et al. 2004; Lee and Reinisch 2006; Chen et al. 2009; Ambili et al. 2012). During morning hours as solar radiation start to build, the rapid ionization in the lower $\mathrm{F}$ region causes a decrease in $\mathrm{HmF} 2$ values ( $\mathrm{Su}$ et al. 1998; Ambili et al. 2012; Sripathi 2012). The HmF2 diurnal variations during post-noon hours are dominant for all the seasons and this characteristic was more prominent during 2011, may be due to rapid fluctuation in solar activities. The increase in PRE of (Sun et al. 2012) $E \times B$ drift velocity as well as decrease in ion production help the plasma to be uplifted as well as transported to other latitudes, causing sudden enhancement in HmF2 during post-sunset (18.00-20.00 hrs LT) hours. Moreover, there is noticeable association between the appearance of sunrise undulation phenomenon in $\mathrm{HmF} 2$ produced by photochemistry (Ambili et al. 2012), and strong uplifted plasma at sunset (Ambili et al. 2013) around the magnetic equator. This association is more prevalent in COSMIC-RO observation than in IRI model output (see figure 3). During the autumn of 2010 ( 287 km), $2011(\sim 420 \mathrm{~km})$ and $2012(\sim 331 \mathrm{~km})$ and the winter of $2012(\sim 338 \mathrm{~km})$ this phenomenon noticeably occurred, but in the IRI-2007 model output, it is not visible. At noon, the so called 'noon-bite-out' phenomenon also plays a dominant role in ionospheric electrodynamics causing slight decreases in NmF2 (figure $2 \mathrm{a}-\mathrm{c}$ ) with fairly constant HmF2 (figure 3a-c) (Lee and Reinisch 2006; Sripathi 2012).

Also, during HSA (2011 and 2012) period, the noticeable enhancement (Chen et al. 2009) in magnitude of hour-to-hour seasonal averaged HmF2 values with respect to LSA period are prevalent to both IRI-2007 (up to 45 and $56 \mathrm{~km}$ ) model and COSMIC-RO (185 and $96.5 \mathrm{~km}$ ) observations.

\subsection{TIEC and BIEC diurnal and seasonal variations}

Figures $4(\mathrm{a}-\mathrm{j})$ and $5(\mathrm{a}-\mathrm{j})$ represent the diurnal variations in BIEC and TIEC, obtained from COSMIC satellite measurements and IRI-2007 model output, over the observation area for different seasons during 2008-2012. Both IECs (TIEC and BIEC) exhibit collateral trend in diurnal variations with larger spread (or standard deviation) in case of IRI-2007. However, the diurnal-dip occurred during pre-dawn hours for all the seasons and thereafter, both IECs started to increase, reaching maximum at noon (Chakraborty et al. 1999). The daytime peak values are almost 5-9 times higher than the diurnal-dip values in case of COSMIC satellite measurements, whereas for IRI-2007 model it is $5-50$ for all seasons of 2008 to 2012 , undergoing diminishing trend with increasing solar activity. In general, the autumn (spring) and winter correspond to maximum and minimum TIEC (BIEC) concentration along with the values of spring (autumn) and summer lies in between them (figures 4, 5; Kenpankho et al. 2011; Liu et al. 2006; Sethi and Dabas 2006), which partly support the report in Sripathi (2012). In comparison to yearly variability, 2011 shows the most significant evolution in IECs variation during daytime, with large positive deviations (figures $4 \mathrm{~d}, 5 \mathrm{~d}$; up to 11TECU for BIEC and 25.13TECU for TIEC, considering all the seasons) in season-to-season 

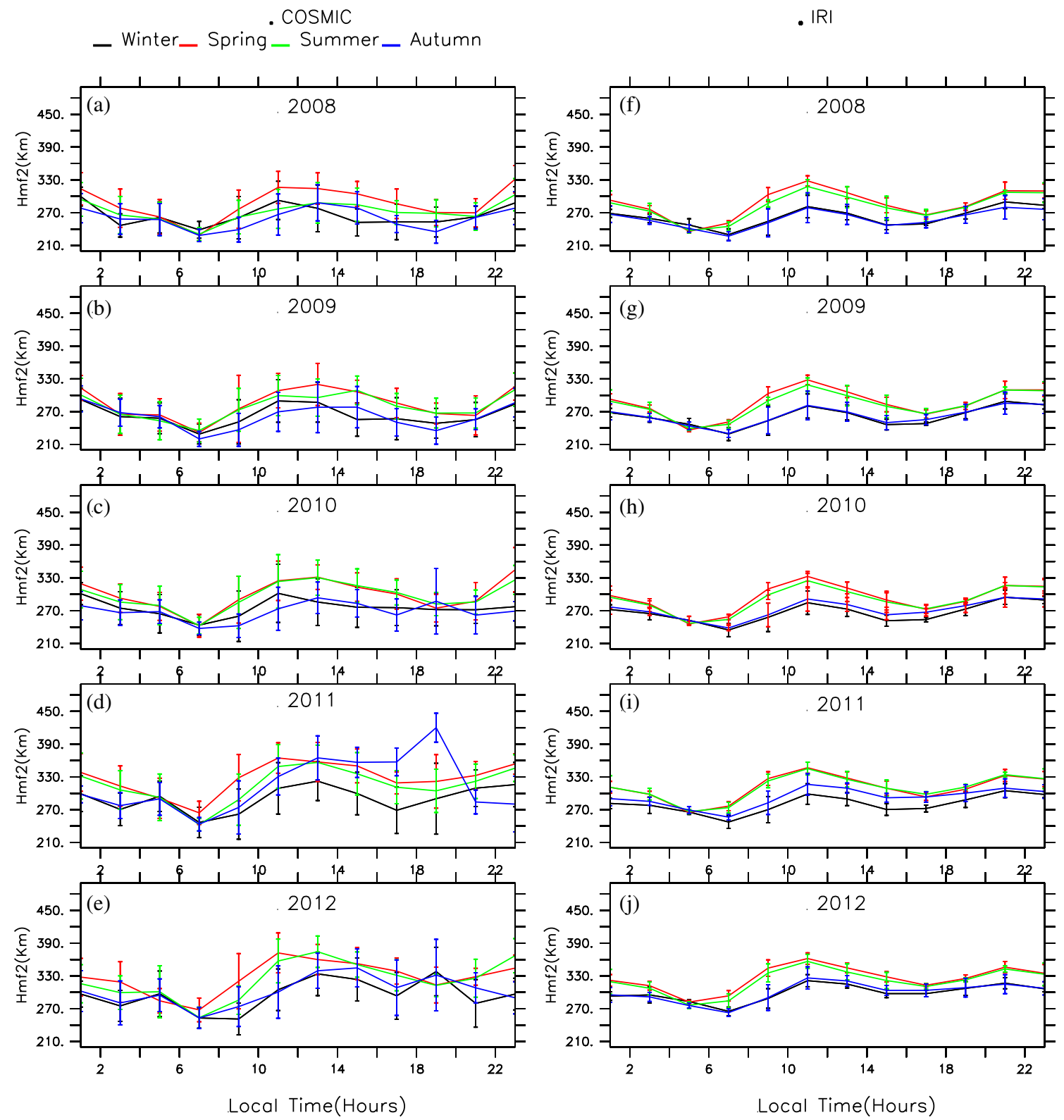

Figure 3. The diurnal variation in $\mathrm{HmF} 2$ using COSMIC-RO observations over low-latitude region $\left(15^{\circ}-30^{\circ} \mathrm{N}, 80^{\circ}-95^{\circ} \mathrm{E}\right)$ and IRI-2007 model output at Kolkata. The left panels are for COSMIC-RO measurements for the years: (a) 2008; (b) 2009; (c) 2010; (d) 2011 and (e) 2012. The right panels are for IRI-2007 model output for the years: (a) 2008; (b) 2009; (c) 2010; (d) 2011 and (e) 2012 respectively. Different colours represent different seasons. Vertical bars denote the standard deviation.

values with respect to winter. But, in the case of remaining years, these deviations are comparatively small, with large fluctuation in the summer of 2012, when IRI-2007 model output shows relatively more diffusive trend in seasonal averaged IECs. During prolonged solar minimum in 2008, the ratio between seasonal averaged TIEC and BIEC values at different LT lies in between 1.33 and 3.10 for COSMIC satellite measurements, whereas for IRI-2007 it varies from 1.2 to 3.5. This ratio (graph not shown) always remains less than 3.1 and 3.5 for both options, respectively, with least values (1.1-2.1) at noon. The height difference between top and bottom side of the ionosphere is, on an average, $100 \mathrm{~km}$. The Ne concentration in this extra height definitely helps to account for this excessive TIEC in comparison to BIEC, except at noon, when the $\mathrm{Ne}$ concentration in bottom side ascend to the decisive level due to longer persistence of intense solar radiation and achieves relatively higher BIEC in comparison to TIEC.

\subsection{NmF2, HmF2, BIEC and TIEC annual variations}

Figure $6(\mathrm{a}-\mathrm{d})$ shows the plot of monthly averaged NmF2, HmF2, BIEC, and TIEC obtained 

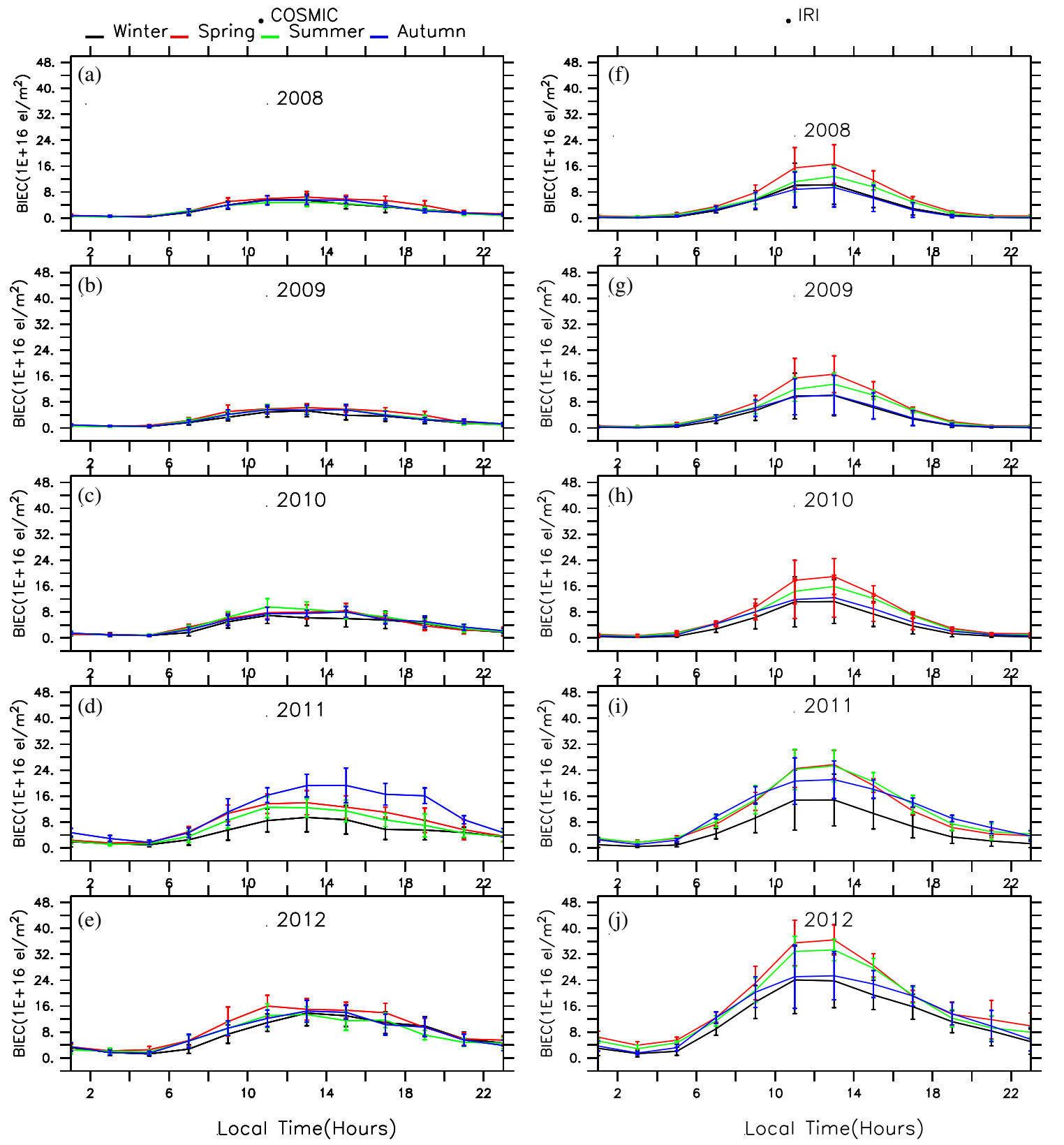

Figure 4. The diurnal variation in BIEC using COSMIC-RO observations over low-latitude region $\left(15^{\circ}-30^{\circ} \mathrm{N}, 80^{\circ}-95^{\circ} \mathrm{E}\right)$ and IRI-2007 model output at Kolkata. The left panels are for COSMIC-RO measurements for the years: (a) 2008; (b) 2009; (c) 2010; (d) 2011 and (e) 2012. The right panels are for IRI-2007 model output for the years: (a) 2008; (b) 2009; (c) 2010; (d) 2011 and (e) 2012. Different colours represent different seasons. Vertical bars denote the standard deviation.

from COSMIC-RO (cross symbol) measurements and IRI-2007 (dash symbol) model output in the observation area for the time period 20082012. The gap in each panel (during midnight) is due to non-availability of data during the period 22.00-02.00 hrs LT. It may be seen from this figure that during March-April and SeptemberNovember, there are two strong peaks in NmF2, BIEC, and TIEC values with larger spread from mean, which are represented using vertical bars. The monthly averaged values of $\mathrm{HmF} 2$ show single yearly-peak during May-June (figure 6) for all the years, except 2012. In 2012, monthly averaged values of HmF2 (379 and $348 \mathrm{~km}$ at noontime and midnight, respectively) exhibit yearlypeak during July-September. Also, in case of yearly-dip, monthly averaged values of $\mathrm{NmF} 2$, BIEC, and TIEC exhibit the occurrence of twindips associated to the months: December-January and June-July, whereas HmF2 values exhibit the yearly-dip in the month of December. It is now observed that the NmF2, BIEC, and TIEC values have persistent semi-annual variation. But the $\mathrm{HmF} 2$ has annual variation under LSA as well as 

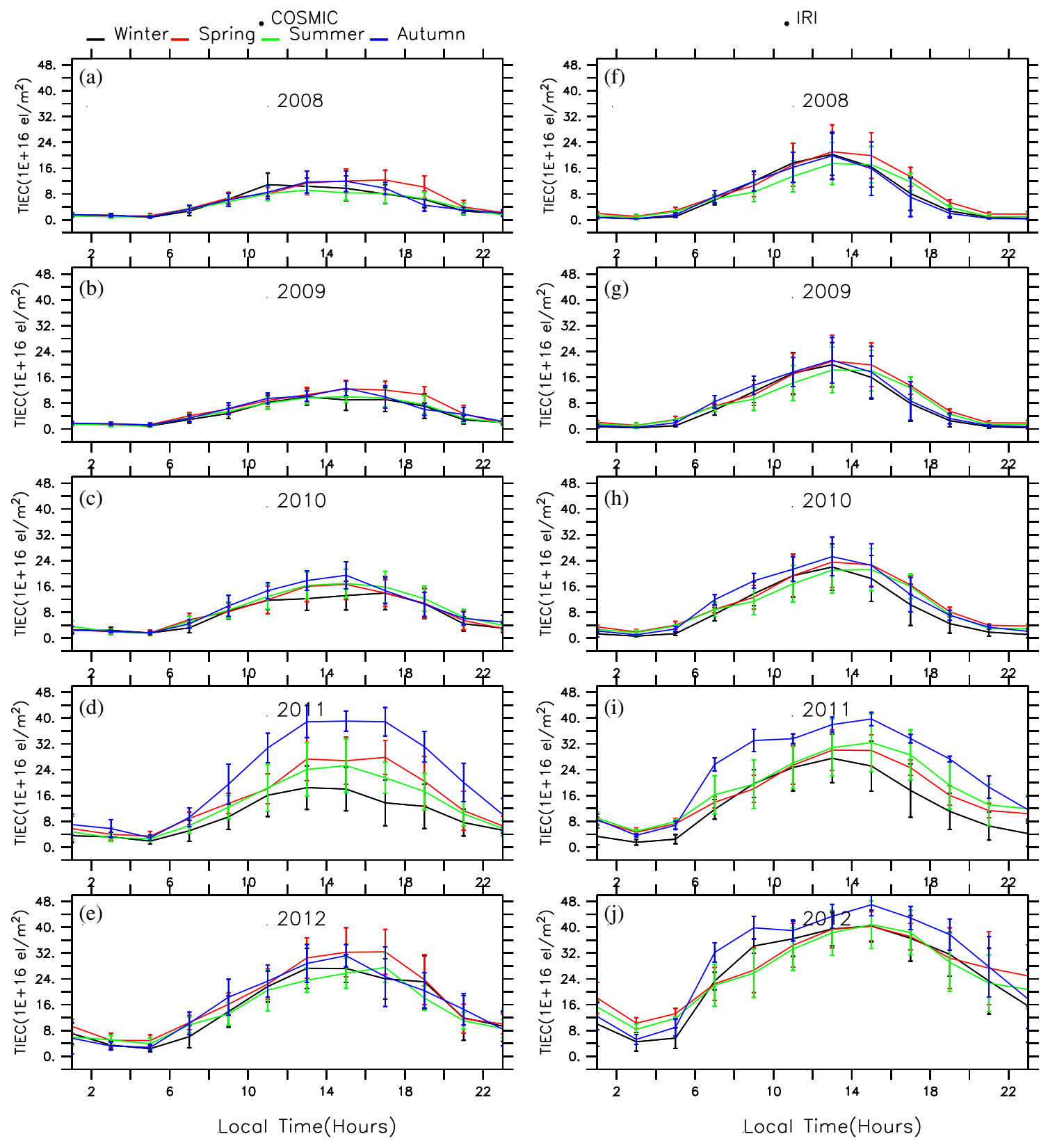

Figure 5. The diurnal variation in TIEC using COSMIC-RO observations over low-latitude region $\left(15^{\circ}-30^{\circ} \mathrm{N}, 80^{\circ}-95^{\circ} \mathrm{E}\right)$ and IRI-2007 model output at Kolkata. The left panels are for COSMIC-RO measurements for the years: (a) 2008; (b) 2009; (c) 2010; (d) 2011 and (e) 2012. The right panels are for IRI-2007 model output for the years: (a) 2008; (b) 2009; (c) 2010; (d) 2011 and (e) 2012 respectively. Different colours represent different seasons. Vertical bars denote the standard deviation.

HSA conditions over this region. Some earlier studies have reported that over equatorial region, the ionosphere exhibits annual (in case of $\mathrm{HmF} 2$ ) and semi-annual (in case of NmF2, BIEC, TIEC) variations (Kawamura et al. 2002; Sripathi 2012), which are constrained by the solar zenith angle, photochemistry (Ambili et al. 2012, 2013), meridional neutral winds (Alken et al. 2008), and the ratio between [O] and [N2] (Su et al. 1998; Chen et al. 2009) variation. Generally, at midnight, monthly averaged values of all the parameters, except HmF2 (minor enhancement occurred during LSA), differ by nearly $2.1-8.3$ times less than that of noontime values in case of COSMIC satellite observation, whereas for IRI-2007 model output, those values are periodically diffusive for month-tomonth (1.3-42 in case of TIEC and NmF2 and 3-61 in case of BIEC) with minimum in June and maximum in November. This difference has significantly decreased during rising solar activity for both options. Additionally, a robust ascent in all the parameters during 2011 may be attributed to the significant change in solar activity (figure 1a), which proves the Sun's control over ionosphere 

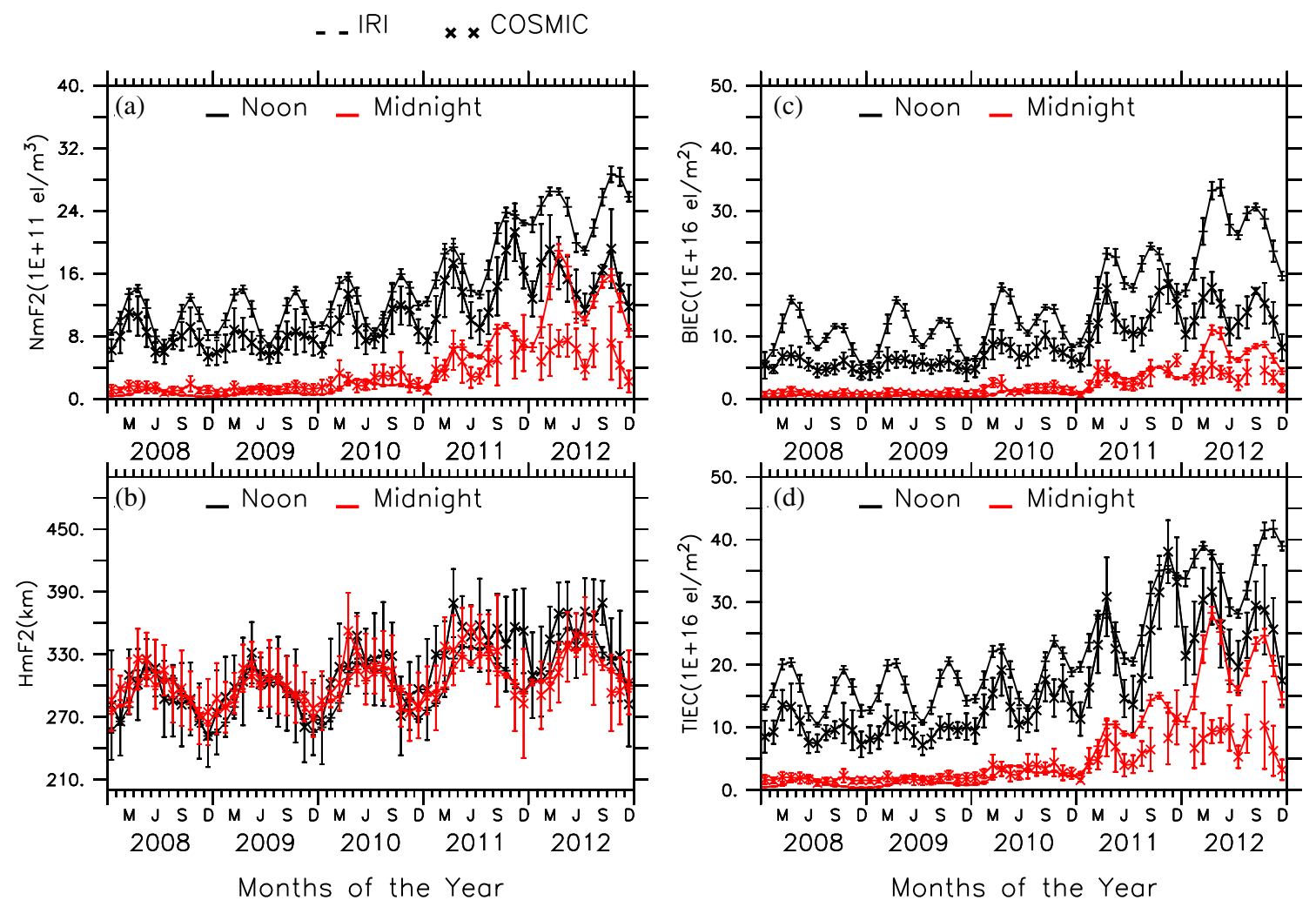

Figure 6. Time series plot of monthly averaged (a) NmF2; (b) HmF2; (c) BIEC and (d) TIEC using COSMIC-RO (cross symbols) observations over low-latitude region $\left(15^{\circ}-30^{\circ} \mathrm{N}, 80^{\circ}-95^{\circ} \mathrm{E}\right.$ ) and IRI-2007(dash symbols) model output at Kolkata during 2008-2012. The black and red lines represent the noontime (10.00-14.00 hrs LT) and midnight (22.00-02.00 hrs LT) time outputs. Vertical bars denote the standard deviation.

(Rishbeth and Muller-Wodarg 2006; Chen et al. 2009; Sripathi 2012). It may be mentioned here that the $\mathrm{HmF} 2$ variation over equatorial region is dependent on vertical $E \times B$ drift velocity and over low latitude it is dependent on the meridional neutral winds (Su et al. 1998; Lee and Reinisch 2006; Alken et al. 2008; Sripathi 2012) below it, where both of these phenomena have diurnal (Ambili et al. 2012, 2013) and seasonal variations (Chen et al. 2009). At noon (10.00-14.00 hrs LT), the rate of ion production (in bottom and topside ionosphere) due to solar radiation and at midnight (22.00-02.00 hrs LT) the late PRE upward velocity are the dominating factors for rising HmF2 level, especially during LSA period (Lee and Reinisch 2006). The monthly averaged $\mathrm{HmF} 2, \mathrm{NmF} 2$, BIEC, and TIEC values obtained from both options have shown large differences (in 2012) at noon $(58 \mathrm{~km}$, $14.12 \mathrm{E}+11 \mathrm{el} / \mathrm{m}^{3}, 18.53 \mathrm{TECU}$, and $21.5 \mathrm{TECU}$ ) in comparison to midnight $\left(46 \mathrm{~km}, 11.81 \mathrm{E}+11 \mathrm{el} / \mathrm{m}^{3}\right.$, 6.22TECU, and 19TECU). Till 2010 December, at midnight, monthly averaged $\mathrm{HmF} 2$ values, particularly at the yearly-dip, tended to be slightly higher than that of noontime values. During noon and midnight, the variations in observed IECs exhibit high level ( $86.4 \%$ and $85 \%$ ) of collateral propensity, which is consistent with the model result ( $83 \%$ and
$98 \%$ ) also. Here it may be observed that the TIEC accumulates higher values, in $53-57 \%$ cases, than BIEC for both observed and model result.

\section{Conclusion}

To study the climatology of low-latitude ionosphere at Kolkata, we have analyzed the COSMIC-RO VED profiles over the region $15^{\circ}-30^{\circ} \mathrm{N}$ and $80^{\circ}$ $95^{\circ} \mathrm{E}$ and compared the result with IRI-2007 model output. This type of study using LEO satellite based information has not been done in recent times over this region. The diurnal, monthly, seasonal, and yearly variations of $\mathrm{NmF} 2, \mathrm{HmF} 2$, BIEC, and TIEC were investigated for the time period 1 January 2008 to 31 December 2012. The seasonal mean values of NmF2, BIEC, and TIEC have shown more or less similar trends in diurnal variation with diurnal-peak around noon to postnoon hours and diurnal-dip around pre-sunrise hours for both model and observed profiles. In addition, the post-noon discrepancies imparted in the observed and model profiles are indeed more intense during all the seasons. The night-time evolutions in all the parameters are more prominent than those of daytime as one moves from LSA 
to HSA conditions. The monthly averaged NmF2, BIEC, and TIEC have sustained higher values in March-April and September-November (autumn) months, while that of HmF2 achieved higher values during May-June (spring) months. Therefore, the Ne concentration in spring and autumn seasons are significantly dominant in the climatological behaviour of ionosphere over this region. Our analysis also indicates that $\mathrm{HmF} 2$ exhibit annual variation with yearly-dip during winter, while others (NmF2, BIEC, and TIEC) exhibit semi-annual variation (figure 6). The major discrepancies observed between COSMIC-RO observation and IRI-2007 model outputs are:

- The differences between diurnal-dip and diurnalpeak values in all the parameters are considerably higher in IRI-2007 model output in comparison to COSMIC-RO observation, especially during rising solar activity.

- The sudden enhancement of observed HmF2, occurring in the autumn seasons (figure 3c-e) of 2010-2012 and the winter season (figure 3e) of 2012 , is inconsistent with the model result.

- In case of monthly averaged NmF2 and IECs, the model outcomes markedly overestimate (nearly in $73 \%$ cases) the observed values, especially during rising solar activity period and for monthly averaged $\mathrm{HmF} 2$ it underestimates (nearly in $76 \%$ cases) the observed value.

Also, the ratio of TIEC and BIEC decreased rapidly towards noon, which helps to advocate that the Ne concentration in the bottom side of ionosphere attained higher values, due to longer persistence of intense solar radiation, in comparison to topside part. The significant evolution in variation of all the parameters during 2011 may be due to transition of solar activity from one stage to another. In 2012, the level of monthly averaged peak and dip values have increased by significant amounts (figure 6), which could be due to HSA. Moreover, the discrepancies observed in variation pattern, obtained from both options, can help the research community to understand the recent trends of ionospheric parameters, especially over this region and develop the IRI model in a more effective way for better fitting to the observed profiles.

\section{Acknowledgements}

The research work presented here has been carried out through financial assistance from Council of Scientific \&Industrial Research (CSIR), India. The COSMIC satellite data are taken from the website http://www.cosmic.ucar.edu. The authors would like to thank the World Data Centre (Geomagnetic
Data Centre), Kyoto, Japan for providing geomagnetic storms, $K p$ index data and UKSSD, UK for providing $F 10.7 \mathrm{~cm}$ solar flux data. The authors would also like to acknowledge the reviewers for their constructive comments.

\section{References}

Alken P, Maus S, Emmert J and Drob D P 2008 Improved horizontal wind model HWM07 enables estimation of equatorial ionospheric electric fields from satellite magnetic measurements; Geophys. Res. Lett. 35 L11105, doi: 10.1029/2008GL033580.

Ambili K M, St-Maurice J P and Choudhary R K 2012 On the sunrise oscillation of the $\mathrm{F}$ region in the equatorial ionosphere; Geophys. Res. Lett. 39(16) L16102, doi: 10.1029/2012GL052876.

Ambili K M, Choudhary R K, St-Maurice J P and Chau J L 2013 Night-time vertical plasma drifts and the occurrence of sunrise undulation at the dip equator: A study using Jicamarca incoherent backscatter radar measurements; Geophys. Res. Lett. 40(21) 5570-5575, L16102, doi: 10.1002/2013GL057837.

Aragon-Angel A, Hemandez-Pajares M, Juan J M and Sanz J 2009 Obtaining more accurate electron density profiles from bending angle with GPS occultation data: FORMOSAT-3/COSMIC constellation; Adv. Space Res. 43 1694-1701, doi: 10.1016/j.asr.2008.10.034.

Bhar J N, Das Gupta A and Basu S 1970 Studies on Fregion irregularities at low latitude from scintillations of satellite signal; Radio Sci. 5(6) 939-942.

Bilitza D and Reinisch B W 2008 International reference ionosphere 2007: Improvements and new parameters; $A d v$. Space Res. 42 599-609, doi: 10.1016/j.asr.2007.07.048.

Chakraborty S K, DasGupta A, Ray S and Banerjee S 1999 Long-term observations of VHF scintillation and total electron content near the crest of the equatorial anomaly in the Indian longitude zone; Radio Sci. 34, doi: 10.1029/98RS02576, ISSN: 0048-6604.

Chen Y, Liu L, Wan W, Yue X and Su S 2009 Solar activity dependence of the topside ionosphere at low latitudes; J. Geophys. Res. 114 A08306, doi: 10.1029/2008JA013957.

Chuo Y J, Lee C C, Chen W S and Reinisch B W 2011 Comparison between bottom side ionospheric profile parameters retrieved from FORMOSAT3 measurements and ground-based observations collected at Jicamarca; J. Atmos. Sol.-Terr. Phys. 73 1665-1673, doi: 10.1016/j.jastp.2011.02.021.

Das A, Das Gupta A and Ray S 2010 Characteristics of L-band (1.5 GHz) and VHF (244 MHz) amplitude scintillations recorded at Kolkata during 1996-2006 and development of models for the occurrence probability of scintillations using neural network; J. Atmos. Sol.-Terr. Phys. 72 685-704, doi: 10.1016/j.jastp.2010.03.010.

Das Gupta A, Paul A and Das A 2007 Ionospheric total electron content (TEC) studies with GPS in the equatorial region; Indian J. Radio Space Phys. 36 278-292.

Hwang C, Tseng T, Lin T, Švehla D and Schreiner B 2009 Precise orbit determination for the FORMOSAT3/COSMIC satellite mission using GPS; J. Geodesy $8 \mathbf{3}$ 477-489, doi: 10.1007/s00190-008-0256-3.

Kawamura S, Balan N, Otsuka Y and Fukao S 2002 Annual and semi-annual variations of the multitude ionosphere under low solar activity; J. Geophys. Res. 107(A8) 1166, doi: 10.1029/2001JA000267.

Kenpankho P, Watthanasangmechai K, Supnithi P, Tsugawa T and Maruyama T 2011 Comparison of GPS 
TEC measurements with IRI TEC prediction at the equatorial latitude station, Chumphon, Thailand; Earth Planet. Space 63 365-370.

Lee C C and Reinisch B W 2006 Quiet-condition hmF2, $\mathrm{NmF} 2$, and $\mathrm{B}_{0}$ variations at Jicamarca and comparison with IRI-2001 during solar maximum; J. Atmos. Sol.-Terr. Phys. 68 2138-2146.

Lee C C and Reinisch B W 2007 Quiet-condition variations in the scale height at F2-layer peak at Jicamarca during solar minimum and maximum; J. Ann. Geophys. 25 2541-2550.

Liu J Y, Lin $\mathrm{C} \mathrm{H}$, Chen $\mathrm{Y}$ I, Lin $\mathrm{Y}$ C, Fang $\mathrm{T}$ W, Chen C H, Chen Y C and Hwang J J 2006 Solar flare signature of the ionospheric GPS total electron content; J. Geophys. Res. (USA) 111A5 A05308.

Park Y, Kwak Y, Ahn B, Park Y and Cho L 2010 Ionospheric F2-layer semi-annual variation in middle latitude by solar activity; J. Astron. Space Sci. 27(4) 319-327, doi: 0.5140/JASS.2010.27.4.319.

Paul A, Das A and Das Gupta A 2011 Characteristics of SBAS grid sizes around the northern crest of the equatorial ionization anomaly; J. Atmos. Sol.-Terr. Phys. 73 1715-1722, doi: 10.1016/j.jastp.2011.03.008.
Rishbeth H and Muller-Wodarg I C F 2006 Why is there more ionosphere in January than in July? The annual asymmetry in the F2-layer; Ann. Geophys. 24 32933311.

Sethi N K and Dabas R S 2006 Predicted and measured bottom side total electron content under high and moderate solar activity conditions over New Delhi; Indian J. Radio Space Phys. 35 335-343.

Sethi N K, Dabas R S and Vohra V K 2004 Diurnal and seasonal variations of $\mathrm{hmF} 2$ deduced from digital ionosonde over New Delhi and its comparison with IRI-2001; Ann. Geophys. 22 453-458.

Sripathi S 2012 COSMIC observations of ionospheric density profiles over Indian region: Ionospheric conditions during extremely low solar activity period; Indian J. Radio Space Phys. 41 98-109.

Su Y Z, Bailey G J and Oyama K I 1998 Annual and seasonal variations in the low-latitude topside ionosphere; Ann. Geophys. 16 974-985.

Sun S J, Ban P P, Chen C, Xu Z W and Zhao Z W 2012 On the vertical drift of ionospheric F layer during disturbance time: Results from ionosondes; J. Geophys. Res. 117 A01303, doi: 10.1029/2011JA017106. 